\title{
ANALISIS EFEKTIVITAS BIAYA TERAPI KOMBINASI MOOD STABILIZER DAN ANTIPSIKOTIK PADA PASIEN GANGGUAN AFEKTIF BIPOLAR DI RAWAT INAP RSJ GRHASIA YOGYAKARTA
}

\section{Cost Effectiveness Analysis Of Combination Mood Stabilizer And Antipsychotic Therapy In Bipolar Affective Disorder Patients At Grhasia Mental Hospital Yogyakarta}

\section{Novi Milasari ${ }^{\text {* }}$ \\ Dyah Aryani Perwitasari}

Sawitri $3^{3}$

*IFakultas Farmasi, Universitas Ahmad Dahlan, Yogyakarta, DI Yogyakarta, Indonesia

2Fakultas Farmasi, Universitas Ahmad Dahlan, Yogyakarta, DI Yogyakarta, Indonesia

3Rumah Sakit Jiwa Grhasia Yogyakarta, Sleman, DI Yogyakarta, Indonesia

*email: novil708045036@webmail.uad.ac.id

\begin{abstract}
Abstrak
Gangguan afektif bipolar merupakan gangguan jiwa yang bersifat episodik dan ditandai oleh gejala-gejala manik, hipomanik, depresi, dan campuran, biasanya rekuren serta dapat berlangsung seumur hidup. Pasien gangguan afektif bipolar memiliki biaya pengobatan tahunan empat kali lipat dari pasien yang tidak mengalami gangguan afektif bipolar. Penelitian ini bertujuan untuk menganalisis efektivitas biaya terapi kombinasi mood stabilizer dengan antipsikotik pada pasien gangguan afektif bipolar di Rawat Inap Rumah Sakit Jiwa Grhasia Yogyakarta. Metode penelitian ini merupakan penelitian deskriptif dengan pengambilan data secara retrospektif dari rekam medik dan data biaya medik langsung selama pasien rawat inap pada tahun 2018. Subyek penelitian ini adalah pasien rawat inap Rumah Sakit Jiwa Grhasia dengan diagnosis gangguan afektif bipolar episode mania dengan gejala psikotik (F3I.2) yang mendapatkan kombinasi terapi mood stabilizer dan antipsikotik. Hasil penelitian didapatkan pada pasien gangguan afektif bipolar rawat inap sebanyak 46 pasien yang memenuhi kriteria inklusi. Rata-rata biaya medik langsung kombinasi natrium divalproat (Rp.6.319.933) dan kombinasi lithium (Rp. 5.705.953). Rata-rata lama rawat inap kombinasi natrium divalproat 25,79 hari dan lama rawat inap kombinasi lithium 25,75 hari dengan nilai $P$ 0,991 sehingga tidak ada perbedaan yang bermakna. Berdasarkan tabel efektivitas biaya, kombinasi lithium memiliki biaya lebih tinggi dan efektivitas lebih tinggi dibandingkan kombinasi natrium divalproat. Hasil perhitungan nilai ICER yaitu Rp. - 15.349/hari yang berarti kombinasi lithium dapat menghemat biaya Rp 15.349 tiap pengurangan I hari lama rawat inap. Kesimpulan dari penelitian ini bahwa kombinasi lithium-antipsikotik atipikal-tipikal lebih cost effective dan dapat menghemat biaya Rp I5.349 tiap pengurangan I hari lama rawat inap dibandingkan kombinasi natrium divalproat-antipsikotik atipikaltipikal pada pasien gangguan afektif bipolar episode mania dengan gejala psikotik.
\end{abstract}

\begin{abstract}
Bipolar affective disorder is an episodic mental disorder characterized by manic, hypomanic, depressive, and mixed episod, usually recurring and can last a lifetime. Patient with bipolar disorder have annual medical cost that were four times those of patients without bipolar disorder. The aim of this study is to analyze the costeffectiveness of combination therapy between mood stabilizers and antipsychotics in patients with bipolar affective disorder at Grhasia Mental Hospital Yogyakarta. This study is a descriptive study with retrospective using medical record and direct medical cost data during Januari-Desember 2018 period. Subjects are patients who were diagnosed with bipolar affective disorder manic episod (F3I.2) and received a combination of mood stabilizer an antipsychotic therapy. The results were obtained in 46 patients with affective disorder who met the inclusion criteria. The average direct medical cost of sodium divalproate group was IDR 6.319.933 per day and in the lithium group was IDR 5.705 .953 per day. The average length of stay in the sodium divalproate combination was 25,79 days and in the lithium combination was 25,75 days with p-value 0,99 I so there was no significant difference. Based on the cost-effectiveness analysis table, the lithium combination has a higher cost and higher effectiveness than the sodium divalproate combination. The result of the calculation of the ICER value is $R p$. - I5,349 / day which means that lithium combination can save IDR 15.349 per I day reduction in length of stay. The conclusion of this study is that the combination of lithium-antipsychotic therapy is more cost-effective and can save IDR 15,349 per I day reduction in length of stay than combination natrium divalproat-antipsychotic therapy in patients manic episode bipolar affective disorder with psychotic symptoms.
\end{abstract}




\section{PENDAHULUAN}

Kesehatan jiwa merupakan bagian yang tidak terpisahkan dari kesehatan dan unsur utama dalam terwujudnya kualitas hidup manusia yang utuh. Salah satu gangguan jiwa yang masih kurang dipahami masyarakat yaitu gangguan afektif bipolar (Ikawati dan Anurogo, 2018). Gangguan afektif bipolar merupakan gangguan jiwa yang bersifat episodik dan ditandai oleh gejala-gejala manik, hipomanik, depresi, dan campuran, biasanya rekuren serta dapat berlangsung seumur hidup (Kementrian Kesehatan, 2015).

Menurut data Riset Kesehatan Dasar tahun 2018 menunjukkan bahwa prevalensi gangguan mental emosional termasuk di dalamnya gangguan afektif bipolar menunjukkan sekitar 9,8\% dari penduduk di Indonesia. Provinsi dengan prevalensi gangguan mental emosional tertinggi adalah Sulawesi Tengah, Sulawesi Selatan, Jawa Barat, DI Yogyakarta, dan Nusa Tenggara Timur (Dinas Kesehatan Republik Indonesia, 2018). Berdasarkan data laporan rumah sakit RSJ Grhasia Yogyakarta pada tahun 2018 menyatakan bahwa gangguan afektif bipolar termasuk urutan keempat dari sepuluh besar penyakit rawat inap (SIMRS Grhasia Yogyakarta, 2018).

Penelitian yang dilakukan di RSJ Grhasia Yogyakarta menunjukkan bahwa mood stabilizer yang paling banyak digunakan adalah lithium. Antipsikotik atipikal yang paling banyak digunakan adalah clozapine. Antipsikotik tipikal yang paling banyak digunakan adalah haloperidol (Falita, 2013). Kombinasi pengobatan yang paling banyak diresepkan untuk episode mania yaitu mood stabilizer ditambah antipsikotik tipikal dan antipsikotik atipikal (Putri, 2016).

Pemberian mood stabilizer pada pasien gangguan afektif bipolar dapat menimbulkan efek yang berbeda pada pasien yang akan mempengaruhi lama rawat inap. Length of Stay (LOS) menjadi salah satu parameter yang penting untuk menentukan efektivitas biaya terapi untuk gangguan afektif bipolar (Keck et al., 1996). Penelitian pada pasien gangguan afektif bipolar memiliki biaya pengobatan tahunan empat kali lipat dari pasien yang tidak mengalami gangguan afektif bipolar (Stender \& Health, 2002).

Tipe studi farmakoekonomi meliputi empat metode analisis ini bukan hanya mempertimbangkan efektivitas, keamanan, dan kualitas obat yang dibandingkan, tetapi juga aspek ekonominya. Karena aspek ekonomi atau unit moneter menjadi prinsip dasar kajian farmakoekonomi, hasil kajian yang dilakukan diharapkan dapat memberikan masukan untuk menetapkan penggunaan yang paling efisien dari sumber daya kesehatan yang terbatas jumlahnya (Kemenkes RI, 2013). Analisis efektivitas biaya adalah suatu bentuk analisis ekonomi yang membandingkan biaya dan hasil relatif (efek) dari dua tindakan atau lebih (Desu, 2018). Analisis efektivitas biaya cukup sederhana dan banyak digunakan untuk kajian farmakoekonomi untuk membandingkan dua atau lebih intervensi kesehatan yang memberikan besaran efek berbeda (Rascati, 2014). Dengan analisis yang mengukur biaya sekaligus hasilnya ini, pengguna dapat menetapkan bentuk intervensi kesehatan yang paling efisien membutuhkan biaya termurah untuk hasil pengobatan yang menjadi tujuan intervensi tersebut (Andayani, 2013).

Pada penggunaan metode analisis efektivitas biaya perlu dilakukan penghitungan rasio biaya rerata incremental cost-effectiveness ratio (ICER). Dengan ICER dapat diketahui besarnya biaya tambahan untuk setiap perubahan satu unit efektivitas biaya. Selain itu, untuk mempermudah pengambilan kesimpulan alternatif mana yang memberikan efektivitas biaya terbaik, pada kajian dengan metode analisis efektivitas biaya dapat digunakan tabel efektivitas biaya (Andayani, 20I3).

Oleh karena itu, penanganan yang tepat pada kasus gangguan afektif bipolar sangat penting sehingga memerlukan pemantauan efektivitas terapi dan pertimbangan biaya. Penelitian ini akan membandingkan dua mood stabilizer yaitu natrium divalproat dan lithium yang telah dikombinasi antipsikotik tipikal dan antipiskotik atipikal. Hal ini berdasarkan hasil penelitian 
yang dilakukan Putri (2016) di RSJ Ghrasia Yogyakarta menunjukkan bahwa kombinasi pengobatan yang paling banyak diresepkan untuk pasien gangguan afektif bipolar episode mania yaitu mood stabilizer ditambah antipsikotik tipikal dan antipsikotik atipikal. Pemantauan efektivitas terapi diperoleh dari lama rawat inap pasien. Untuk pemantauan efektivitas biaya dilakukan dengan analisis farmakoekonomi yang hasil pemantauannya memberikan saran dokter dalam mengambil keputusan untuk terapi pasien (Wardati \& Indrawati, 2018)

Bersadarkan uraian diatas, maka perlu dilakukan penelitian analisis efektivitas biaya terapi kombinasi mood stabilizer dan antipsikotik pada pasien gangguan afektif bipolar dengan menggunakan metode costeffectiveness analysis mengingat penelitian terkait masih jarang dilakukan terutama di Indonesia. Penelitian ini bertujuan untuk menganalisis efektivitas biaya terapi kombinasi mood stabilizer dan antipsikotik pada pasien gangguan afektif bipolar di Rawat Inap Rumah Sakit Jiwa Grhasia Yogyakarta.

\section{METODOLOGI}

Penelitian ini dilakukan di Rumah Sakit Jiwa Grhasia Yogyakarta periode Januari sampai dengan Desember 2018. Desain penelitian yang dilakukan yaitu penelitian deskriptif dengan pengambilan data secara retrospektif. Data yang digunakan data sekunder berupa data rekam medik dan data biaya medik langsung selama pasien rawat inap. Pengambilan sampel sebanyak 46 pasien dilakukan dengan metode total sampling yaitu semua data sampel yang masuk kriteria inklusi akan diambil sebagai sampel penelitian. Sejumlah 46 pasien dengan diagnosis gangguan afektif bipolar episode mania dengan gejala psikotik (ICD-I0:F3I.2) yang telah memenuhi kriteria inklusi dibagi menjadi dua kombinasi yaitu kombinasi natrium divalproat $(n=38)$ dan kombinasi lithium $(n=8)$.

Teknik pengumpulan data dilakukan secara retrospektif. Pengambilan data pasien melalui rekam medik yang memenuhi kriteria inklusi dan data biaya medik langsung yang diperoleh dari bagian keuangan rumah sakit. Penelitian ini menggunakan parameter yaitu lama rawat inap pasien dan total biaya medik langsung berupa biaya administrasi dan akomodasi, biaya obat, biaya tindakan bangsal, dan biaya klinik dan penunjang.

Kemudian data yang diperoleh dianalisis dengan penghitungan biaya medik langsung dan efektivitas obat. Analisis efektivitas biaya menggunakan tabel efektivitas biaya dan analisis ICER. Hasil yang diperoleh dapat disimpulkan bahwa obat mana yang paling cost-effective pada pasien gangguan bipolar episode mania dengan gejala psikotik.

\section{HASIL DAN PEMBAHASAN}

\section{A. Karakteristik Pasien}

Tabel I. Karakteristik Pasien Gangguan Afektif bipolar di RSJ Grhasia Yogyakarta

\begin{tabular}{|c|c|c|c|c|}
\hline \multirow[t]{2}{*}{ Karakteristik } & \multicolumn{2}{|c|}{ Frekuensi (n,\%) } & \multirow{2}{*}{$\begin{array}{l}\text { Total } \\
(n, \%) \\
n=46\end{array}$} & \multirow{2}{*}{$\begin{array}{l}\text { Mean } \\
\pm \text { SD }\end{array}$} \\
\hline & $\begin{array}{c}\text { Natrium } \\
\text { divalproat } \\
(n=38)\end{array}$ & $\begin{array}{l}\text { Lithium } \\
\qquad(n=8)\end{array}$ & & \\
\hline \multicolumn{5}{|l|}{ Jenis Kelamin } \\
\hline Laki-laki & $18(39,1)$ & $4(8,7)$ & $22(47,8)$ & \\
\hline Perempuan & $20(43,5)$ & $4(8,7)$ & $24(52,5)$ & \\
\hline Usia & & & & $\begin{array}{l}38,07 \\
\pm 10,30\end{array}$ \\
\hline 17-29 tahun & II $(23,9)$ & I $(2,2)$ & $12(26,1)$ & \\
\hline $30-44$ tahun & $17(37)$ & $5(10,9)$ & $22(47,8)$ & \\
\hline 45-59 tahun & $10(2 \mathrm{I}, 7)$ & $2(4,3)$ & $12(26, I)$ & \\
\hline \multicolumn{5}{|l|}{$\begin{array}{l}\text { Tingkat } \\
\text { Pendidikan }\end{array}$} \\
\hline Dasar (SD) & $5(10,9)$ & $\mathrm{I}(2,2)$ & $6(13)$ & \\
\hline $\begin{array}{l}\text { Menengah (SMP- } \\
\text { SMA) }\end{array}$ & $22(47,8)$ & $4(8,7)$ & $26(56,5)$ & \\
\hline Tinggi (DIII-SI) & II $(23,9)$ & $3(6,5)$ & $14(30,4)$ & \\
\hline \multicolumn{5}{|l|}{ Pekerjaan } \\
\hline Bekerja & $10(2 \mid, 7)$ & $6(13)$ & $16(34,8)$ & \\
\hline Tidak Bekerja & $28(60,9)$ & $2(4,3)$ & $30(65,3)$ & \\
\hline
\end{tabular}

Hasil pada tabel I menunjukkan pasien perempuan lebih banyak sejumlah 24 pasien (52,5\%) sedangkan laki-laki semulah 22 pasien (47,8 \%). Hasil tersebut sesuai dengan penelitian yang dilakukan oleh Gumintang (2018) yang menunjukkan bahwa jumlah pasien gangguan afektif bipolar perempuan (59\%) lebih banyak 
daripada laki-laki (4I\%). Berdasarkan usia mayoritas usia pasien berada di 30-44 tahun yaitu sejumlah 22 pasien $(47,8 \%)$. Hasil ini sesuai dengan penelitian yang dilakukan oleh Putri (2016) pasien gangguan afektif bipolar di RSJ Grhasia lebih banyak berusia 36-45 tahun dibandingkan kombinasi usia lain. Sedangkan hal ini berbeda dengan hasil penelitian yang dilakukan oleh National Comorbidity Survey Replicatioan yang menyatakan bahwa kasus gangguan afektif bipolar lebih besar terjadi pada kombinasi usia 18-29 tahun sebesar 4,7\% (NIMH, 20I7). Pada usia remaja akhir atau dewasa muda cenderung mengalami penundaan pengobatan yang lebih lama, resiko lebih besar mengalami keparahan gejala depresi, dan tingkat kecemasan yang lebih tinggi (Joslyn et al., 2016)

Berdasarkan tingkat pendidikan, hasil penelitian menunjukkan bahwa pasien dengan tingkat pendidikan menengah (SMP-SMA) yang paling banyak mengalami gangguan afektif bipolar yaitu 56,5\% (26 pasien) dibandingkan kombinasi lain. Hasil ini sesuai dengan penelitian yang dilakukan Johan (2017) pada pasien gangguan afektif bipolar menunjukkan hasil bahwa pasien dengan tingkat pendidikan SLTA/SMK paling banyak yang mengalami gangguan afektif bipolar yaitu 53,57\% (I 5 pasien) dibandingkan pasien dengan tingkat pendidikan SD dan Sarjana. Belum ditemukan data mengenai hubungan antara gangguan afektif bipolar dengan tingkat pendidikan, namun tingkat pendidikan berhubungan dengan masalah perekonomian (Kuruvilla \& Jacob, 2007).

Berdasarkan pekerjaan, hasil penelitian menunjukkan bahwa pasien yang tidak bekerja berjumlah lebih banyak yaitu 65,2\% (30 pasien) dibandingkan dengan pasien yang bekerja yaitu 34,8\% (16 pasien). Penelitian yang dilakukan Johan (2017) menunjukkan hasil yang sama yaitu pasien dengan presentase terbanyak yaitu pasien yang tidak bekerja berjumlah 42,86\% ( 12 pasien). Gangguan afektif bipolar sering mengalami kekambuhan meskipun dalam keadaan sedang terapi obat, resiko angka kekambuhan masih tetap tinggi. Sering terjadinya kekambuhan dapat menganggu dalam hubungan dengan keluarga, sosial dan pekerjaan. Sehingga pasien yang mengalami gangguan afektif bipolar banyak kehilangan pekerjaan karena menurunnya produktivitas (Amir, 2010).

\section{B. Analisis Biaya Medik Langsung}

Tabel II. Analisis Rata-Rata Biaya Medik Langsung Terapi Kombinasi Natrium Divalproat dan Kombinasi Lithium pada Pasien Gangguan Afektif Bipolar

\begin{tabular}{|c|c|c|c|}
\hline \multirow{2}{*}{ Kategori } & \multicolumn{2}{|c|}{ Biaya Rata-Rata (Rp) } & \multirow{2}{*}{ Nilai p } \\
\cline { 2 - 3 } & $\begin{array}{c}\text { Natrium } \\
\text { divalproat }\end{array}$ & Lithium & \\
\hline $\begin{array}{c}\text { Biaya } \\
\text { akomodasi \& } \\
\text { administrasi }\end{array}$ & 2.541 .381 & 2.946 .937 & 0,377 \\
\hline $\begin{array}{c}\text { Biaya obat } \\
\text { Biaya } \\
\text { tindakan } \\
\text { bangsal }\end{array}$ & 763.036 & 622.383 & 0,258 \\
\hline $\begin{array}{c}\text { Biaya klinik \& } \\
\text { penunjang }\end{array}$ & 218.540 & 88.828 & 0,227 \\
\hline Total & 5.705 .953 & 6.319 .933 & 0,435 \\
\hline
\end{tabular}

Pada penelitian ini dilakukan analisis perhitungan biaya. Pada tabel II, rata-rata total biaya medik langsung pada kombinasi natrium divalproat yaitu Rp 5.705.953/pasien dan kombinasi lithium Rp 6.319.933/pasien. Dilihat dari hasil yang diperoleh pasien gangguan afektif bipolar yang menggunakan natrium divalproat biaya yang diperlukan lebih rendah dibandingkan dengan pasien yang menggunakan lithium tetapi secara statistik perbedaanya tidak bermakna. Hal ini sesuai dengan penelitian yang dilakukan oleh Revicki et al (2005) pada pasien gangguan afektif bipolar biaya pada kombinasi divalproex dan kombinasi lithium secara statistik tidak ada perbedaan yang bermakna. 


\section{Outcome Terapi}

Tabel III. Perhitungan Rata-Rata Length of Stay Terapi Kombinasi Natrium Divalproat dan Kombinasi Lithium Pasien Gangguan Afektif Bipolar

\begin{tabular}{|c|c|c|}
\hline $\begin{array}{c}\text { Terapi } \\
\text { Kombinasi }\end{array}$ & $\begin{array}{c}\text { Rata-rata } \\
\text { Length of Stay } \\
\text { (hari) }\end{array}$ & Nilai p \\
\hline $\begin{array}{c}\text { Natrium } \\
\text { divalproat }\end{array}$ & 25,79 & 0,991 \\
\hline Lithium & 25,75 & \\
\hline
\end{tabular}

Pada penelitian ini penilaian outcome terapi mood stabilizer dan antipsikotik diperoleh dari lama rawat inap. Pada tabel III menunjukkan kombinasi natrium divalproat-antipsikotik atipikal-tipikal diperolah rata-rata lama rawat inap adalah 25,79 hari sedangkan pada kombinasi lithium-antipsikotik atipikal-tipikal adalah 25,75 hari. Berdasarkan hasil statistik diperoleh nilai p-value yaitu 0,99I artinya secara statistik tidak ada perbedaan yang bermakna antar kombinasi. Namun berdasarkan kemaknaan klinis ada perbedaan yang bermakna yaitu kombinasi lithium-antipsikotik atipikal-tipikal lebih efektif dilihat dari nilai rata-rata lama rawat inap lebih cepat dibandingkan kombinasi natrium divalproat-antipsikotik atipikal-tipikal.

Hasil penelitian yang dilakukan (Dalkilic et al., 2000) pada pasien rawat inap gangguan afektif bipolar bahwa secara statistik tidak ada perbedaan yang bermakna lama rawat inap antara pengobatan dengan lithium dan pengobatan dengan divalproex. Penelitian lain yang dilakukan oleh Revicki et al., (2005) pada dua kombinasi yaitu pasien yang mendapat terapi natrium divalproex dan lithium hasil yang diperoleh tidak ada perbedaan yang bermakna secara statistik antara kombinasi lithium dan natrium divalproex berdasarkan lama rawat inap pasien.

\section{Analisis Efektivitas Biaya}

Tabel IV. Biaya Per Hari Terapi Kombinasi Natrium Divalproat dan Kombinasi Lithium Pasien Gangguan Afektif Bipolar

\begin{tabular}{|c|c|c|c|}
\hline $\begin{array}{c}\text { Terapi } \\
\text { Kombinasi }\end{array}$ & $\begin{array}{c}\text { Rata-rata } \\
\text { Biaya (Rp) }\end{array}$ & $\begin{array}{c}\text { Outcome } \\
\text { LOS (hari) }\end{array}$ & $\begin{array}{c}\text { Biaya per } \\
\text { hari } \\
\text { (Rp/hari) }\end{array}$ \\
\hline $\begin{array}{c}\text { Natrium } \\
\text { divalproat }\end{array}$ & 5.705 .953 & 25,79 & $221.246,72$ \\
\hline Lithium & 6.319 .933 & 25,75 & $245.434,29$ \\
\hline
\end{tabular}

Berdasarkan perhitungan, biaya per hari pasien gangguan afektif bipolar dengan terapi kombinasi natrium divalproat adalah Rp. 22 I.246,72/hari dan kombinasi lithium adalah Rp. 245.434,29/hari. Dari perhitungan ini menunjukkan bahwa kombinasi natrium divalproat memiliki biaya per hari lebih murah dibandingkan kombinasi lithium.

Tabel V. Tabel Efektivitas-Biaya

\begin{tabular}{|c|c|c|c|}
\hline $\begin{array}{c}\text { Efektivitas- } \\
\text { biaya }\end{array}$ & $\begin{array}{c}\text { Biaya } \\
\text { lebih } \\
\text { rendah }\end{array}$ & $\begin{array}{c}\text { Biaya } \\
\text { sama }\end{array}$ & $\begin{array}{c}\text { Biaya lebih } \\
\text { tinggi }\end{array}$ \\
\hline $\begin{array}{c}\text { Efektivitas } \\
\text { lebih rendah }\end{array}$ & $\mathrm{A}$ & $\mathrm{B}$ & $\mathrm{C}$ \\
\hline $\begin{array}{c}\text { Efektivitas } \\
\text { sama }\end{array}$ & $\mathrm{D}$ & $\mathrm{E}$ & $\mathrm{F}$ \\
\hline $\begin{array}{c}\text { Efektivitas } \\
\text { lebih tinggi }\end{array}$ & $\mathrm{G}$ & $\mathrm{H}$ & $\begin{array}{c}\text { Lithium } \\
\text { terhadap } \\
\text { natrium } \\
\text { divalproat }\end{array}$ \\
\hline
\end{tabular}

Berdasarkan tabel efektivitas biaya, kombinasi lithium memiliki biaya lebih tinggi dan efektivitas lebih tinggi dibandingkan kombinasi natrium divalproat. Sehingga dapat disimpulkan bahwa kombinasi lithium-antipsikotik atipikaltipikal lebih cost effective pada pasien gangguan afektif bipolar episode mania dengan gejala psikotik dibandingkan kombinasi natrium divalproat-antipsikotik atipikal-tipikal.

Hasil ini tidak sesuai dengan penelitian yang dilakukan oleh Li \& Aggarwal (20II) pada pasien gangguan afektif bipolar dibagi menjadi dua kombinasi yaitu kombinasi valproate dan lithium menunjukkan hasil penggunaan valproate cenderung lebih hemat biaya untuk sistem perawatan kesehatan dan mengurangi 
beban keuangan pasien dibandingkan lithium.

Penelitian lain yang dilakukan Keck et al (1996) rata rata biaya pada pasien gangguan afektif bipolar yang menggunakan terapi divalproex lebih hemat per pasien dibandingkan pasien yang menggunakan terapi lithium.

Tabel VI. Perhitungan ICER Terapi Kombinasi Natrium Divalproat dan Kombinasi Lithium pada Pasien Gangguan Afektif Bipolar

\begin{tabular}{|c|c|c|c|c|c|}
\hline $\begin{array}{c}\text { Terapi } \\
\text { Kombinasi }\end{array}$ & $\begin{array}{c}\text { Biaya } \\
\text { (Rp) }\end{array}$ & $\begin{array}{c}\text { LOS } \\
\text { (har } \\
\text { i) }\end{array}$ & $\begin{array}{c}\Delta \text { Biaya } \\
\text { (Rp) }\end{array}$ & $\begin{array}{c}\Delta \text { L } \\
\text { OS } \\
\text { (ha } \\
\text { ri) }\end{array}$ & $\begin{array}{c}\text { ICER } \\
\text { (Rp/h } \\
\text { ari) }\end{array}$ \\
\hline Lithium & 6.319 .933 & $\begin{array}{c}25,7 \\
5\end{array}$ & 613.980 & - & - \\
\hline $\begin{array}{c}\text { Natrium } \\
\text { divalproat }\end{array}$ & 5.705 .953 & $\begin{array}{c}25,7 \\
9\end{array}$ & & & \\
\hline
\end{tabular}

Selanjutnya untuk perhitungan nilai ICER, diperoleh hasil negatif yaitu Rp. -I5.349/hari. Hasil ini menunjukkan bahwa penggunaan terapi kombinasi lithium-antipsikotik atipikal-tipikal dapat menghemat biaya Rp I5.349 tiap pengurangan I hari lama rawat inap dibandingkan kombinasi natrium divalproat.

\section{KESIMPULAN}

Hasil dari penelitian ini dapat disimpulkan bahwa kombinasi lithium-antipsikotik atipikal-tipikal lebih cost effective dan dapat menghemat biaya Rp 15.349 tiap pengurangan I hari lama rawat inap dibandingkan kombinasi natrium divalproat-antipsikotik atipikaltipikal pada pasien rawat inap gangguan afektif bipolar episode mania dengan gejala psikotik di RSJ Grhasia Yogyakarta.

\section{UCAPAN TERIMA KASIH}

Ucapan terima kasih disampaikan kepada Fakultas Farmasi Universitas Ahmad Dahlan, Staff Rekam Medik dan Staff Keuangan Rumah Sakit Jiwa Grhasia Yogyakarta.

\section{REFERENSI}

I. Ikawati, Zullies; Anurogo, D. (20/8). Tata Laksana Terapi Penyakit Sistem Syaraf Pusat (Pertama). Yogyakarta: Bursa IImu.

2. Kementrian Kesehatan. (20I5). PEDOMAN NASIONAL PELAYANAN KEDOKTERAN JIWA.

3. Dinas Kesehatan Republik Indonesia. (2018). Riset Kesehatan Dasar.

4. SIMRS Ghrasia Yogyakarta. (2018). Laporan Data 10 Besar Penyakit Rawat Inap RSJ Ghrasia Yogyakarta. Yogyakarta.

5. Falita. (20I3). Pola Pengobatan Pada Pasien Gangguan Bipolar Di Rumah Sakit Grhasia Yogyakarta Pada Tahun 2009-201I. I-32. Retrieved from http://etd.repository.ugm.ac.id/index.php?mod=pe nelitian detail\&sub=PenelitianDetail\&act=view\&ty $\mathrm{p}=$ html\&buku_id $=64876$

6. Putri, kurnia indriany. (2016). Evaluasi peresepan obat pasien gangguan bipolar di instalasi rawat inap rumah sakit jiwa grhasia tahun 2014 kurnia indriany putri.

7. Kemenkes RI. (20I3). Buku Pedoman Farmakoekonomi. Jakarta: Kementrian Kesehatan Republik Indonesia.

8. Desu, P. K. (2018). Pharmacoeconomics: an overview. (January).

9. Rascati, K. L. (20/4). Essentials of Pharmacoeconomics Second Edition. In Lippincott Williams \& Wilkins, a Wolters Kluwer business. https://doi.org/10.1017/CBO978I 107415324.004

10. Andayani, T. M. (20I3). Farmakoekonomi Prinsip dan Metodologi (Pertama). Yogyakarta: Bursa Ilmu.

I I. Keck, P. E., Nabulsi, A. A., Taylor, J. L., Henke, C. J., Chmiel, J. J., Stanton, S. P., \& Bennett, J. A. (1996). A pharmacoeconomic model of divalproex vs. lithium in the acute and prophylactic treatment of bipolar I disorder. Journal of Clinical Psychiatry, 57(5), 213-222.

12. Stender, M., \& Health, D. G. (2002). Health care utilization and costs among privately insured patients with bipolar I disorder. (7), 398-405.

13. Wardati, Y., \& Indrawati, D. K. (20/8). Costeffectiveness analysis of aripiprazole-escitalopram with aripiprazole-agomelatine as bipolar treatment in a pharmacy in Bandung, Indonesia. Drug Invention 
Today, 10(Special Issue 5), 3776-3780.

14. Gumintang, Y. (20/8). Hubungan Faktor Karakteristik Pasien dengan Kejadian Interaksi Obat Antidepresan pada Pasien Rawat Jalan di Rumah sakit Jiwa Grhasia Yogyakarta. Digilib UAD. Retrieved from http://digilib.uad.ac.id/penelitian/Penelitian/detail// 037|4/hubungan-faktor-karateristik-pasiendengan-kejadian-interaksi-obat-antidepresan-padapasien-rawat-jalan-bipolar-di-rumah-sakit-jiwagrhasia-yogyakarta

15. NIMH. (2017). Prevalence of Bipolar Disorder Among Adults. National Institute of Mental Health. Retrieved from https://www.nimh.nih.gov/health/statistics/bipolardisorder.shtml

16. Joslyn, C., Hawes, D. J., Hunt, C., \& Mitchell, P. B. (20I6). Is age of onset associated with severity, prognosis, and clinical features in bipolar disorder? A meta-analytic review. Bipolar Disorders, 18(5), 389-403. https://doi.org//0.1 I I //bdi.12419

17. Johan, ika meliana. (2017). Evaluasi Kerasionalan dan Kuantitas Penggunaan Kombinasi Obat Mood Stabilizer dan Antipsikotik Pada Pasien Bipolar di Rumah Sakit Jiwa Grhasia Yogyakarta. Digilib UAD. Retrieved from http://digilib.uad.ac.id/penelitian/Penelitian/detail/9 6124/evaluasi-kerasionalan-dan-kuantitaspenggunaan-kombinasi-obat-mood-stabilizer-danantipsikotik-pada-pasien-bipolar-di-rumah-sakitjiwa-grhasia-yogyakarta

I8. A. Kuruvilla \& K.S. Jacob. (2007). Poverty, social stress \&amp; mental health. Department of Psychiatry, Christian Medical College, Vellore, India, (October), 273-278. Retrieved from https://www.researchgate.net/profile/Ks Jacob/pu blication $/ 5814418$ Poverty social stress mental health/links/57cff94a08aed67897037669.pdf

19. Amir, N. (2010). Gangguan mood bipolar: kriteria diagnostik dan tatalaksana dengan obat antipsikotika atipik. Jakarta: Badan Penerbit FKUI.

20. Revicki, D. A., Hirschfeld, R. M. A., Ahearn, E. P., Weisler, R. H., Palmer, C., \& Keck, P. E. (2005). Effectiveness and medical costs of divalproex versus lithium in the treatment of bipolar disorder: Results of a naturalistic clinical trial. Journal of Affective Disorders, 86(2-3), 183-193. https://doi.org/10.1016/j.jad.2005.01.002

21. Dalkilic, A., Diaz, E., Baker, C. B., Pearsall, H. R., \& Woods, S. W. (2000). Effects of divalproex versus lithium on length of hospital stay among patients with bipolar disorder. Psychiatric Services, 5I(9), II84-II86.

https://doi.org/10.1176/appi.ps.51.9.1184

22. Li, S. C., \& Aggarwal, S. K. (20II). Estimation of resource utilisation difference between lithium and valproate treatment groups from the VALID study. Journal of Medical Economics, 14(3), 350-356. https://doi.org/ I0.3 I I I/ |3696998.20 I I.58 I32 I 